\title{
Future directions for public health research in emerging infectious diseases
}

\author{
Grant A Hill-Cawthorne $e^{a, b, d}$ and Tania C Sorrella,c
}

${ }^{a}$ Marie Bashir Institute for Infectious Diseases and Biosecurity, University of Sydney, NSW, Australia

b School of Public Health, University of Sydney, NSW, Australia

c Westmead Institute for Medical Research, University of Sydney, NSW, Australia

${ }^{d}$ Corresponding author: grant.hill-cawthorne@sydney.edu.au

\section{Article history}

Publication date: December 2016

Citation: Hill-Cawthorne GA, Sorrell TC.

Future directions for public health research in emerging infectious diseases. Public Health Res Pract. 2016;26(5):e2651655. doi: http://dx.doi.org/10.17061/phrp2651655

\section{Key points}

- New infections will continue to emerge, and public health responsiveness must anticipate this by developing effective, pre-emptive pandemic plans

- Public health research now needs to involve humans, animals and the environment

- Australia is moving towards adopting the concept of Planetary Health, but more funding for research, training and implementation is required

\section{Abstract}

Infectious diseases remain responsible for significant global morbidity and mortality, and diseases emerge and re-emerge in sometimes unpredictable locations and at unpredictable times. Although much is known about how to detect and respond to existing infections, more public health research is needed to predict the likelihood of their emergence and spread, and to improve the precision and timeliness of public health responsiveness. To achieve this, further research is required to develop pathogen genomics from more than just a tool for outbreak investigation to one that will identify and quantify catalysts for emergence within a given population. More research is also needed to develop digital epidemiology techniques to identify syndromic clusters earlier.

Beyond human public health, appreciating how animals and the environment affect disease emergence presents us with a new challenge: to develop truly interdisciplinary research that encompasses all aspects of pathogen surveillance and response. This includes understanding why microorganisms cross species to cause diseases (e.g. from animals to humans), factors that drive spread of infections, and systems research that will result in development of joint responses to outbreaks from different professional, government and international groups. Only then will we be better prepared for the next outbreak.

\section{The need for infectious disease research}

Lately, it seems as if there is a new infectious disease outbreak every few months. In 2016 alone, we have seen the emergence of Zika virus as a public health problem, a resurgence of leishmaniasis driven by the Syrian refugee crisis and, closer to home, outbreaks of legionellosis in central Sydney. Unsurprisingly, the World Economic Forum has now identified the spread of infectious diseases as the second-highest global risk in terms of likelihood and potential impact, second only to water crises. ${ }^{1}$ Around 60 years ago, with the advent of routine vaccination and antibiotics, many people questioned the continuing usefulness of infectious diseases as a specialty. ${ }^{2}$ Hence, a key 
research question is: how can we better predict where and when new infectious diseases are going to emerge?

In recent years, there has been a greater appreciation of the interactions between the growing human population; increased global connectivity and movement of people, animals and plants; and the impact that humans are having on the planet. This has generated a number of new 'movements': One Health, Eco Health and Planetary Health, to name only a few. ${ }^{3,4}$ All of these new interdisciplinary areas emphasise just how well we have set up circumstances for infections to emerge. These include changing the climate, moving animals (and many humans) across the globe, increased land use and re-use, and intensive farming practices. These changes have also had the knock-on effect of increasing noncommunicable diseases such as diabetes, as well as unforeseen immunosuppressive and other comorbid effects. In addition, we have seen a number of older infections re-emerge because of the incessant march of antimicrobial resistance. ${ }^{5}$

Logically, these changes must focus attention on two key areas for public health research - how do we predict and prepare for the next outbreak (and, once prepared, detect it in a timely manner), and how do we broaden our framework to better include animals and the environment?

\section{Preparing for, and responding to, the next outbreak}

Australia's National Framework for Communicable Disease Control recognises that research needs to be an integral part of preparation for, and response to, communicable disease outbreaks. ${ }^{6}$ There are three requirements for an outbreak to occur: a susceptible host population, a virulent microorganism that can be transmitted between hosts, and a vector or route of transmission. However, research outputs to date are only now starting to allow us to predict where these three factors might coexist. Reviews of the preparation for, and response to, the 2014 outbreak of Ebola virus disease have noted that, although these factors coexisted in West Africa, the global community's ability to rapidly produce and widely share the knowledge required to contain the outbreak was inadequate. ${ }^{7}$ Models of what drives Ebola virus emergence and sustains human-to-human transmission have now been developed and serve as a template for predicting future disease incursions. ${ }^{8}$

Understanding microbial emergence and spread is critical to effective public health programs. This can be achieved by examining the pathogen itself (e.g. genomic risk assessment - mutations that may predispose to spread or virulence), identifying the presence of animal reservoirs and vectors and their 'competence' for carrying specific pathogens (e.g. Aedes albopictus in the Torres Strait Islands and Ae. aegypti in northern Australia), and population immunity (e.g. influenza viruses, re-emergence of Bordetella pertussis).
Australia's current response to emerging infectious diseases is heavily reliant on passive surveillance and notification of a select list of diseases. Relying on conventional clinical, epidemiological and laboratory systems to identify disease emergence is slow, and risks missing an evolving syndrome. Critical to a 21 st century public health response is the ability to perform realtime genomic surveillance, understand the catalysts of transmission within a population, and identify early the appearance of new syndromes or clusters of symptoms in a community.

Pathogen genomics has been a growing technology during the past decade and its role in public health surveillance has been reviewed extensively. ${ }^{9}$ In the US, its use in foodborne pathogen detection and response has led to increased discriminatory power and the identification of more, and smaller, outbreak clusters before they can take root. ${ }^{10}$ Anecdotally, the same has occurred in Australia. The next step requires adapting genomics beyond outbreak identification and control to pre-emptive identification of those organisms that are likely to mutate and adapt to mammals, or to vectors. The genetic determinants that affect virulence - either increasing the risk of severe infections or allowing them to spread 'below the radar' - also need to be identified.

Perhaps even more important than the pathogen itself is human behaviour - a key driver of emergence and transmission. Multiple factors are relevant, including increased urbanisation and encroachment on animal habitats, land clearing, intensive farming practices, mass air travel, poor infection control practices and overuse of antimicrobial agents. In an individual outbreak, transmission of disease is conventionally assessed through contact tracing in public health responses, but this is a slow and imprecise tool. Pathogen genomics has increased the potential for identifying super-spreaders and other catalysts of transmission, and for identifying transmission events much more precisely. Combining such information with traditional contact tracing, together with further research into social networks, will provide greater clarity and inform predictive models. Such models have helped shape responses to Ebola virus and influenza virus, but the development of ongoing interoutbreak models of social network interactions is needed to guide future outbreak responses. ${ }^{11}$

The first hint of an emerging infection or outbreak is not usually the identification of a causative microorganism, but rather a cluster of people with similar symptoms beyond the usual background rate. Digital epidemiology is a growing discipline that combines webbased information with geospatial locations. ${ }^{12}$ An example of where this has been used with some sensitivity is Google Flu Trends, which accurately predicted rates of influenza-like illness in the US in 2011 and 2012, but then significantly overpredicted them in 2013. ${ }^{13}$ Digital epidemiology can be combined with existing syndromic surveillance collected from emergency departments 
and sentinel general practices to give early hints that an outbreak is occurring.

\section{Research within a Planetary Health framework}

The majority of emerging infections are zoonotic. Understanding the dynamics of preceding animal outbreaks can inform any subsequent human outbreak response. Currently, the majority of our surveillance systems are focused on human infections, and this is partly because of the human focus of the International Health Regulations (IHR). ${ }^{14}$ However, detecting a disease when it has already appeared in large enough numbers in humans to cause a visible outbreak is clearly too late. There is now a much greater appreciation of the need to monitor and detect infectious agents in the animal population, before they are able to amplify and spill over into humans. This timely identification offers a rapid control opportunity through pre-exposure vaccination, isolation or culling of affected animals.

As a result, surveillance approaches need to become more creative and include aspects such as vegetation density, rainfall, animal and human population movements, and vector presence and persistence. Understanding how these are related to urbanisation, town planning, travel and global trade are crucial to knowing where and when infections are likely to emerge. To do so requires not only implementation of the IHR in the 132 countries that do not yet have the capacity to detect and respond to outbreaks, but also requires a core capacity to identify diseases emerging in animals and environmental vectors.

A corollary to this approach is an absolute need for the pursuit of integrated, systems-based research. In particular, the health component will need to be expanded to include animal and ecological health, so that we can understand how these silos can continue to work more closely together. Planetary Health encompasses this interdisciplinary approach, with a reframing of human health and a redefinition of prosperity. ${ }^{15}$

\section{Next steps}

Australia is making significant headway in public health research in this area, especially in the area of antimicrobial resistance. A step in the right direction is the establishment of an National Health and Medical Research Council (NHMRC) Centre of Research Excellence in Protecting the Public from Emerging Infectious Diseases, with a focus on pathogen emergence and spread, effective public health responses, and policy development and implementation. One model of coworking between ministries of health and agriculture, demonstrated by the UK and Australia for tackling antimicrobial resistance, can be effectively adopted in any country with little additional resources required.
To meet future demands, new research programs must ensure a truly interdisciplinary approach to emerging infectious diseases, to break down the traditional barriers between human health funding and other research funding. The new Medical Research Future Fund offers an opportunity to consider truly interdisciplinary, holistic approaches. In addition, there is an urgent requirement to develop international guidelines on data exchange (epidemiological and microbiological) and sample access, and frameworks for the rapid initiation of phase 3 clinical trials during an outbreak.

Infectious diseases have always had the upper hand and continue to surprise us. They are often unpredictable and can leave us with no treatment or vaccine on hand. Continual research in the public health sphere, incorporating a Planetary Health approach, is essential if we are to respond effectively to outbreaks of new and re-emerging infections.

\section{Acknowledgements}

TS is a Sydney Medical School Foundation Fellow whose work is funded by the NHMRC, the University of Sydney and the Sydney Medical School Foundation.

\section{Competing interests}

None declared

\section{Author contributions}

$\mathrm{GH}-\mathrm{C}$ wrote the initial draft of the manuscript. TS and $\mathrm{GH}-\mathrm{C}$ edited the manuscript.

\section{References}

1. World Economic Forum. Global Risks 2015. Geneva: World Economic Forum; 2015 [cited 2016 Oct 5]. Available from: reports.weforum.org/global-risks-2015/

2. Spellberg B. Dr. William H. Stewart: mistaken or maligned? Clin Infect Dis. 2008;47(2):294.

3. Marais B, Crawford J, Iredell J, Ward M, Simpson S, Gilbert L, et al. One world, one health: beyond the Millennium Development Goals. Lancet. 2012;380(9844):805-6.

4. Horton R. Why the unity of life matters for our planetary health. Lancet. 2015;386(9991):323.

5. O'Neill J. Tackling drug-resistant infections globally: final report and recommendations. London: Wellcome Trust, HM Government; 2016 [cited 2016 Oct 5]. Available from: amr-review.org/sites/default/files/160525_Final\%20paper_ with\%20cover.pdf 
6. Commonwealth of Australia. National framework for communicable disease control. Canberra: Commonwealth of Australia; 2014 [cited 2016 Oct 5]. Available from: www.health.gov.au/internet/main/ publishing.nsf/Content/ohp-nat-frame-communic-diseasecontrol.htm

7. Moon S, Sridhar D, Pate MA, Jha AK, Clinton C, Delaunay $S$, et al. Will Ebola change the game? Ten essential reforms before the next pandemic. The report of the Harvard-LSHTM Independent Panel on the Global Response to Ebola. Lancet. 2015;386(10009):2204-21.

8. Alexander KA, Sanderson CE, Marathe M, Lewis BL, Rivers CM, Shaman J, et al. What factors might have led to the emergence of Ebola in West Africa? PLoS Negl Trop Dis. 2015;9(6):e0003652.

9. Steffins I, editor. Molecular epidemiology of human pathogens. Euro Surveill. 2013;18(1).

10. Bakker den HC, Allard MW, Bopp D, Brown EW, Fontana J, Iqbal Z, et al. Rapid whole-genome sequencing for surveillance of Salmonella enterica serovar enteritidis. Emerg Infect Dis. 2014;20(8):1306-14.
11. Poletto C, Gomes MF, Pastore y Piontti A, Rossi L, Bioglio L, Chao DL, et al. Assessing the impact of travel restrictions on international spread of the 2014 West African Ebola epidemic. Euro Surveill. 2014;19(42).

12. Salathé M, Freifeld CC, Mekaru SR, Tomasulo AF, Brownstein JS. Influenza A (H7N9) and the importance of digital epidemiology. N Engl J Med. 2013;369(5):401-4.

13. Butler D. When Google got flu wrong. Nature. 2013;494(7436):155-6.

14. World Health Organization. International Health Regulations 2005. Second edition. Geneva: World Health Organization; 2008 [cited 2016 Oct 5]. Available from: apps.who.int/iris/ bitstream/10665/43883/1/9789241580410_eng.pdf

15. Whitmee S, Haines A, Beyrer C, Boltz F, Capon AG, de Souza Dias BF, et al. Safeguarding human health in the Anthropocene epoch: report of The Rockefeller Foundation-Lancet Commission on planetary health. Lancet. 2015;386(10007):1973-2028.

\section{Copyright: (c) (i) (2)}

(C) 2016 Hill-Cawthorne and Sorrell. This article is licensed under the Creative Commons Attribution-NonCommercial-ShareAlike 4.0 International Licence, which allows others to redistribute, adapt and share this work non-commercially provided they attribute the work and any adapted version of it is distributed under the same Creative Commons licence terms. See: www.creativecommons.org/licenses/by-nc-sa/4.0/ 